\title{
5'-Nuclease PCR Assay of Gliding Bacteria that Kill Skeletonema costatum in Seawater
}

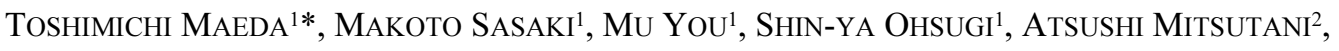 \\ MANABU FURUSHITA ${ }^{1}$ and TSUNEO SHIBA ${ }^{1}$ \\ ${ }^{1}$ Department of Food Science and Technology, National Fisheries University, Shimonoseki, Yamaguchi \\ 759-6595, Japan \\ ${ }^{2}$ Department of Marine Biotechnology, Faculty of Life Science and Biotechnology, Fukuyama University, \\ Fukuyama, Hiroshima 729-0292, Japan
}

(Received June 4, 2003-Accepted August 1, 2003)

A 5'-nuclease PCR assay, targeting 16S rDNA, was developed to detect a group of gliding bacteria that digest Skeletonema costatum cells and are phylogenetically close to Cytophaga latercula. The detection limit was 15 molecules of the target DNA in one reaction mixture. The assay is so strict that the probe did not hybridize to DNA fragments with one nucleotide mismatch, even though the amount of DNA fragments was increased to the order of $10^{10}$ molecules. The assay was applied to DNA extracted from natural seawater of Yoshimi Bay, Hibikinada Sea, Japan, during the period from August 1998 to February 1999. A positive result was obtained only for a seawater sample of September 10, 1998. Among 30 PCR clones obtained from the 5'-nuclease PCR product of the positive sample, 25 clones gave positive results and 4 clones negative results in the assay. The positive clones examined were identical in the structure of the probe region, whereas negative clones had one nucleotide mismatch or deletion. The results indicate that the assay detects only the target sequence even in natural seawater DNA.

Key words: Algicidal bacteria, Algal-lytic bacteria, 16S rDNA, 5'-Nuclease PCR assay

Blooms of Skeletonema costatum have inflicted serious damage on the aquaculture of seaweeds in the coastal waters of Japan, by depleting inorganic nutrients, resulting in a color fading of cultivated Porphyra tenera ${ }^{8}$. During periods of Skeletonema costatum blooms, some gliding bacteria have been reported to be predominant ${ }^{7)}$. These bacteria were capable of digesting the cytoplasm of the alga or of producing algal protoplasts. When the bacteria were inoculated into cultures of Skeletonema costatum, there was a sudden decrease in the size of the algal population. Hence, the bacteria seem to be a potential tool for repressing blooms of Skeletonema costatum, and their ecological relationship to these blooms is of particular interest to the fisheries sector ${ }^{3)}$. In order to examine this relationship in the natural environ-

\footnotetext{
* Corresponding author; E-mail: toshima $@$ fish-u.ac.jp, Tel: $+81-$ 832-86-5111, Fax: +81-832-86-7434
}

ment, it is a prerequisite that the population of such gliding bacteria be quickly determined.

The 5'-Nuclease PCR assay is one of the most rapid methods of detecting a target bacterial DNA. The method utilizes an oligonucleotide probe that is modified with 6carboxyfluorescein (FAM) at the 5'-end and 6-carboxytetramethylrhodamine (TAMRA) at the 3 '-end. The fluorescence energy of FAM (reporter dye) is transferred to TAMRA (quenching dye) by virtue of their proximity when the probe is intact, but not transferred and the fluorescence increases when the probe hybridizes to the target DNA. In brief, the endogenous 5' to 3' nuclease activity of Taq DNA polymerase digests the probe if it hybridizes to a site between primers ${ }^{2,4)}$. FAM and TAMRA are separated far from each other, and the fluorescence of FAM is increased. The speed of this assay is superior to that of other hybridization techniques, because the results can be determined directly 
by measuring fluorescence. Also the system is favorable for determining the hybridization specificity of the probe ${ }^{15}$.

This study attempted to develop a 5'-nuclease PCR assay method for detecting a group of algicidal gliding bacteria that are phylogenetically close to Cytophaga latercula. Although our previous works have isolated 16 gliding bacterial strains and grouped them into clusters A, B, C and D on the basis of $16 \mathrm{~S} \mathrm{rDNA}^{5,8}$, only the strains of the $\mathrm{A} 5$ group in cluster $\mathrm{A}$ are targets in this experiment. The A5 strains share a characteristic nucleotide sequence of $16 \mathrm{~S}$ rDNA, but the others do not.

\section{Materials and Methods}

\section{Bacterial count}

Total bacterial counts were determined under an epifluorescent microscope using 4',6-diamidino-2-phenylindole $(\mathrm{DAPI})^{10)}$. Viable counts of bacteria (CFU counts) were determined using PPES-II agar plate medium ${ }^{14,17)}$. The plates were incubated for two weeks at $20^{\circ} \mathrm{C}$.

\section{DNA extraction from bacterial strains}

Bacterial strains used in this study are summarized in Fig. 1. Strains A5, A11, A14, A15, A20, A38, A12, A16, A 37 and A23 were algal-killing gliding bacteria, which were isolated from Ariake Sea, Japan ${ }^{8}$. Cytophaga latercula ATCC23177, Tenacibaculum maritimum ATCC43398, Psychroflexus gondwanensis LMG13192, Salegentibacter salegens LMG13193, Flavobacterium aquatile IFO15052 and Cytophaga marinoflava IFO14170 were obtained from the American Type Culture Collection, USA (ATCC), the Belgian Co-ordinated Collections of Microorganisms, Belgium (BCCM), and the Institute for Fermentation, Osaka, Japan (IFO). The strains A5, A11, A14, A15 and A20 belonging to group A5 (cluster A) are the target strains for the 5'-nuclease PCR assay developed in this study. The strains A38 and A12 (cluster A), A16 (cluster B), A37 (cluster C) and A23 (cluster D) were excluded from this experiment because of their low distribution frequency ${ }^{5,8}$.

The strains were cultured in a modified PPES-II agar medium $^{14)}$, except for Flavobacterium aquatile which was cultured in a medium containing $4 \mathrm{~g}$ of yeast extract, $10 \mathrm{~g}$ of malt extract, $4 \mathrm{~g}$ of glucose and $20 \mathrm{~g}$ of agar in 1 liter of distilled water ( $\mathrm{pH}$ 7.3). DNA was extracted by a boiling method ${ }^{6}$. Briefly, one bacterial colony was removed from the agar plates, suspended in $100 \mu \mathrm{l}$ of sterilized distilled water in an 1.5-ml microfuge tube, and then boiled for 10 $\mathrm{min}$. After centrifugation at $12,000 \mathrm{~g}$ for $10 \mathrm{~min}$, the supernatant was used as bacterial DNA without further purification.

\section{Fluorogenic probe and PCR primers for 5'-nuclease PCR assay}

A fluorogenic probe, CF8 (5'-TGGCATCGTTTAATAATTAAAGATTTAT-3'), which is specific to the 16S rDNA of A5 group strains, was designed by sequence comparison with other strains and synthesized by Applied Biosystems Japan. The probe region corresponded to Escherichia coli

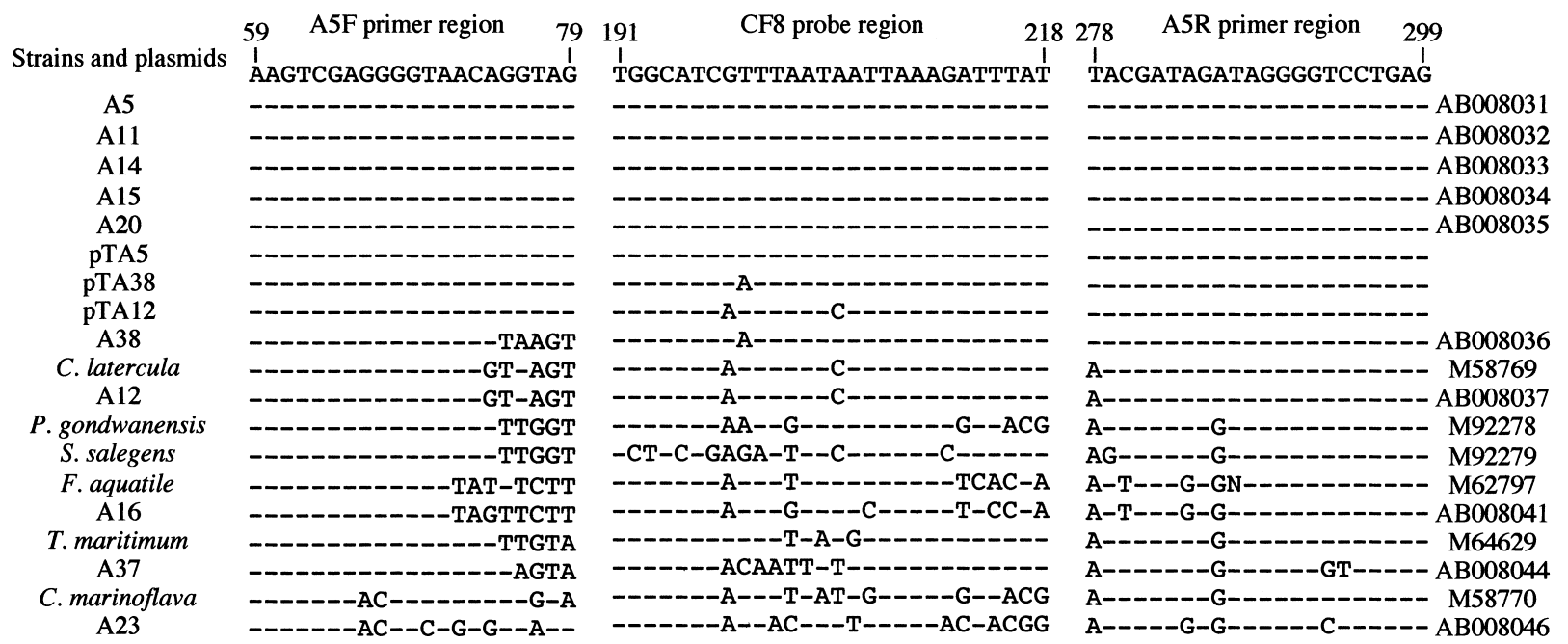

Fig. 1. Sequence difference in primer and probe regions of bacterial strains and plasmids. Hyphens indicate nucleotides identical to A5F/A5R primers and CF8 probe regions. Numbers denote the positions of Escherichia coli $16 \mathrm{~S}$ rDNA ${ }^{1}$. GenBank/EMBL/DDBJ accession numbers of the sequences are shown on the right. C, Cytophaga; P, Psychroflexus; S, Salegentibacter; F, Flavobacterium; T, Tenacibaculum. 
16S rDNA at positions ${ }^{1)} 191$ to 218 . The probe was labeled with 6-carboxyfluorescein (FAM) at the 5'-end and with 6carboxytetramethylrhodamine (TAMRA) at the 3 '-end. The 3' carbon of the 3'-end nucleotide was esterified with phosphate to prevent nucleotide extension. A set of PCR primers specific to group A5, A5F (5'-AAGTCGAGGGGTAACAGGTAG-3') and A5R (5'-CTCAGGACCCCTATCTATCGTA-3'), was designed based on 16S rDNA by sequence comparison. A set of universal PCR primers for bacterial 16S rDNA, 27F (5'-AGAGTTTGATCMTGGCTCAG-3') and 338R (5'-CTGCTGCCTCCCGTAGGAGT-3') ${ }^{15)}$, was also used. The primers were synthesized by Amersham Biosciences Japan. The primers A5F, A5R, 27F and 338R, corresponded to $E$. coli $16 \mathrm{~S}$ rDNA positions ${ }^{1)}$ 59-79, 278-299, 8-27 and 338-357, respectively.

\section{Preparation of chimeric $16 \mathrm{~S}$ rDNA as a target DNA}

DNA fragments that have nucleotide sequences different from the CF8 probe and sequences identical to the $\mathrm{A} 5 \mathrm{~F} /$ A5R primers were needed to examine the specificity of CF8. Since no bacterial DNA fulfils this prerequisite, we constructed chimeric 16S rDNA fragments through recombination of PCR-amplified 16S rDNA of the strains A5, A12 and A38 (Fig. 2). The number of nucleotide changes relative to the $\mathrm{CF} 8$ probe, $\mathrm{A} 5 \mathrm{~F}$ primer and $\mathrm{A} 5 \mathrm{R}$ primer is 1 , 5 and 0 in strain A38, and 2, 5 and 1 in strain A12, respectively (Fig. 1). The PCR mixture $(100 \mu \mathrm{l})$ was composed of 2.5 U of Taq DNA polymerase (Takara Co., Ltd., Japan), 20 nmol of each dNTP, $5 \mu$ of bacterial DNA extract, 100 pmol each of $27 \mathrm{~F}$ and $338 \mathrm{R}$ primers, and $10 \mu \mathrm{l}$ of a ten-fold concentrated buffer $(100 \mathrm{mM}$ Tris- $\mathrm{HCl}, 500 \mathrm{mM} \mathrm{KCl}$, and $15 \mathrm{mM} \mathrm{MgCl}_{2}, \mathrm{pH} 8.3$ ). The $16 \mathrm{~S}$ rDNA was amplified with 30 thermal cycles of $60 \mathrm{~s}$ at $94^{\circ} \mathrm{C}$ and $45 \mathrm{~s}$ at $60^{\circ} \mathrm{C}$, and an additional extension for $300 \mathrm{~s}$ at $72^{\circ} \mathrm{C}$. The PCR was performed with a model PJ2000 DNA Thermal Cycler (Takara Co., Ltd.).

The PCR products were digested with $H$ haI, or double digested with HhaI and EcoT14I. Each fragment was recovered using a Geneclean II kit (BIO 101, Inc. CA, USA) after fractionation by agarose-gel electrophoresis. The A38 fragment between the $H$ haI site and $338 \mathrm{R}$ primer region was ligated with the 27F-HhaI of A5 (Fig. 2A), whereas the HhaI-EcoT14I fragment of A12 was ligated with both the 27F-HhaI and the EcoT14I-338R fragment of A5 (Fig. 2B). The ligated fragments were PCR-amplified again using A5F/A5R primers, and then cloned in E. coli $\mathrm{DH} 5 \alpha$ using pT7Blue T vector (Takara Co., Ltd.). The A5F-A5R PCR product ( $238 \mathrm{bp}$ ) of strain A5 was cloned without any digestion by restriction enzymes. The structures of the plasmids
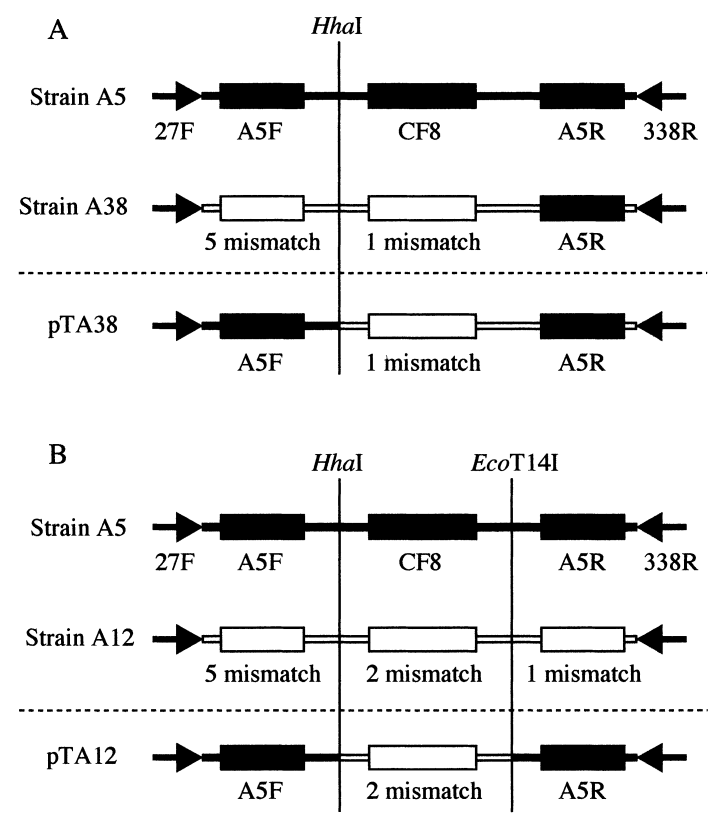

Fig. 2. Construction of chimeric $16 \mathrm{~S}$ rDNA that has 1 mismatch (A) or 2 mismatches (B) in the CF8 probe region. (A): $27 \mathrm{~F}-H$ HaI fragment of strain A5 and HhaI-338R of strain A38 were ligated and cloned in a plasmid vector. The pTA38 plasmid harbored chimeric $16 \mathrm{~S}$ rDNA that has no mismatch in the A5F or A5R primer region but 1 mismatch in the CF8 probe region. (B): $27 \mathrm{~F}-H h a \mathrm{I}$ of strain A5, HhaI-EcoT14I of strain A12 and EcoT14I-338R of strain A5 were ligated and cloned. The pTA12 harbored chimeric $16 \mathrm{~S}$ rDNA that has no mismatch in the A5F or A5R region but 2 mismatches in the CF8 region.

were confirmed by sequencing. The plasmids (pTA5, pTA38 and pTA12) in which chimeric $16 \mathrm{~S}$ rDNA was inserted in the same orientation were used for the experiment.

\section{Nucleotide sequencing}

Nucleotide sequence was determined with a Dye terminator cycle sequencing kit and an automated DNA sequencer, 373S (Applied Biosystems, NJ, USA). Primers designed for the cloning site of pT7Blue T vector, M13M (5'-ACGTTGTAAAACGACGGCCAGT-3') and RVM2 (5'-TCACACAGGAAACAGCTATGACC-3'), were used for the sequencing.

\section{5'-Nuclease PCR assay}

Hybridization of the fluorogenic probe $\mathrm{CF} 8$ to $16 \mathrm{~S}$ rDNA fragments was measured by determining the increase of fluorescence after PCR. Fifty microliters of the PCR assay mixture was composed of 5 pmol of CF8 probe, $1.5 \mathrm{U}$ of Ampli Taq gold (Applied Biosystems), $10 \mathrm{nmol}$ of each $\mathrm{dNTP}, 50 \mathrm{pmol}$ of each primer, $5 \mu \mathrm{l}$ of a ten-fold concen- 
trated buffer (100 mM Tris- $\mathrm{HCl}$ and $500 \mathrm{mM} \mathrm{KCl}, \mathrm{pH} 8.3)$, and $2.0 \mathrm{mM} \mathrm{MgCl}$. The amount of template DNA was $1 \mu \mathrm{l}$ for bacterial DNA extracts, $8 \mu$ for seawater DNA extracts, and as indicated in the text for plasmid DNA. The primers A5F and A5R, or $27 \mathrm{~F}$ and 338R were used. $\mathrm{Mg}^{2+}$ at $2 \mathrm{mM}$ gave the highest specificity. The thermal profile consisted of a hot-start at $95^{\circ} \mathrm{C}$ for 9 minutes and a set of 50 cycles of $60 \mathrm{~s}$ at $94^{\circ} \mathrm{C}, 45 \mathrm{~s}$ at $58^{\circ} \mathrm{C}$ (unless stated otherwise in the text), and $90 \mathrm{~s}$ at $72^{\circ} \mathrm{C}$, followed by an extension at $72^{\circ} \mathrm{C}$ for $300 \mathrm{~s}$. The PCR amplification of the target molecules was checked with an agarose-gel electrophoresis. The concentration of PCR products and plasmid DNA was determined using Hoechst 332589). Briefly, several microliters of each sample was added to $200 \mu \mathrm{l}$ of solution $(0.1 \mu \mathrm{g} / \mathrm{ml}$ of Hoechst 33258, $10 \mathrm{mM}$ Tris-HCl, $1 \mathrm{mM} \mathrm{Na} 2$ EDTA and $200 \mathrm{mM} \mathrm{NaCl}, \mathrm{pH}$ 7.4) and fluorescence at $450 \mathrm{~nm}$ was measured at an excitation wavelength of $350 \mathrm{~nm}$ with a fluorescence spectrophotometer (model RF-5300, Shimadzu, Co., Japan). Ultrapure calf thymus DNA (Sigma-Aldrich, Inc., MO, USA) was used as the standard. To reduce the background fluorescence of remaining probe, the PCR product was ethanol-precipitated and then the fluorescence of the supernatant was measured at an excitation wavelength of $495 \mathrm{~nm}^{16)}$. The hybridization of the probe to the target DNA was indicated by the fluorescence at $518 \mathrm{~nm}$.

\section{Extraction of DNA from natural seawater}

Surface seawater was aseptically collected at two-week intervals, between August 1998 and February 1999, at Yoshimi Bay, Hibiki-nada Sea, Japan. Fifty milliliters of the seawater was filtrated through a membrane filter $(0.2 \mu \mathrm{m}$ pore size and $25 \mathrm{~mm}$ diameter nuclepore membrane, Whatman Inc., Clifton, NJ, USA) and washed twice by additional filtration with $5 \mathrm{ml}$ of a sterilized $3 \% \mathrm{NaCl}$ solution. All glassware was baked at $450^{\circ} \mathrm{C}$ and the membrane filter was autoclaved before use. The filter was put into an $1.5-\mathrm{ml}$ microfuge tube containing $800 \mu \mathrm{l}$ of distilled water and then boiled for $10 \mathrm{~min}$. After removal of the filter, the tube was centrifuged at $12,000 \mathrm{~g}$ for $10 \mathrm{~min}$ and the supernatant was collected. DNA in the supernatant was precipitated using a cold ethanol method ${ }^{13)}$ with a co-precipitating agent (Ethachin-mate, Nippon Gene, Co., Japan), resuspended in $20 \mu \mathrm{l}$ of TE buffer $(10 \mathrm{mM}$ Tris- $\mathrm{HCl}$ and $1 \mathrm{mM}$ EDTA, $\mathrm{pH}$ 8.0), and used as seawater DNA extract without further purification. Eight microliters of the DNA solution was applied to a 50- $\mu$ l volume of 5'-nuclease PCR assay mixture. When a positive result was obtained, the PCR products were cloned in E. coli DH5 $\alpha$ using the vector pT7Blue T, and then the nucleotide sequences of the clones were determined.

\section{Results and Discussion}

The hybridization specificity of probe CF8 was examined using the plasmids pTA5, pTA38 and pTA12, which have different chimeric 16S rDNA fragments. The levels of these plasmids were $0.5 \mathrm{ng}$ per $50 \mu \mathrm{l}$ of reaction mixture. The fragment in pTA5 had the same sequence as the probe, whereas those in pTA38 and pTA12 had one and two mismatches in the probe region, respectively (Fig. 1). All of the fragments had sequences identical to the $\mathrm{A} 5 \mathrm{~F}$ and $\mathrm{A} 5 \mathrm{R}$ primers. As shown in Fig. 3, in all cases, the fluorescence which was measured after 5'-nuclease PCR, decreased as the annealing temperature increased. Although the fluorescence of pTA5 remained higher than that of the no template control, the fluorescence of pTA38 and pTA12 was comparable to or less than that of the control, at temperatures higher than $54^{\circ} \mathrm{C}$. Since PCR products of expected size (238 bp) were obtained in all of the assays (data not shown), the probe hybridized only to pTA5 at these temperatures.

The hybridization specificity of probe CF8 was then examined at $58^{\circ} \mathrm{C}$ at concentrations of target DNA ranging from 1.5 to $1.5 \times 10^{10}$ molecules (from 5 ag to $50 \mathrm{ng}$ of pTA5 and pTA35) in $50 \mu \mathrm{l}$ of the reaction mixture (Fig. 4). The fluorescence of pTA5 was higher than that of the no tem-

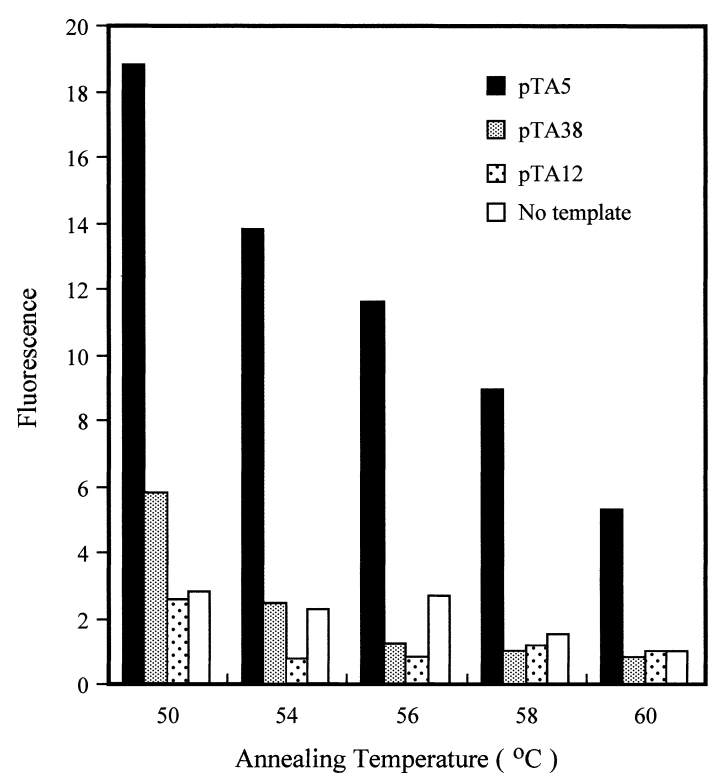

Fig. 3. 5'-Nuclease PCR assay at different annealing temperatures. The assay was performed using the PCR primers A5F and A5R. Three plasmids were used as template DNA: pTA5, pTA38 and pTA12 had 0, 1 and 2 mismatches, respectively, in the probe region, and had sequences identical to the PCR primers. 


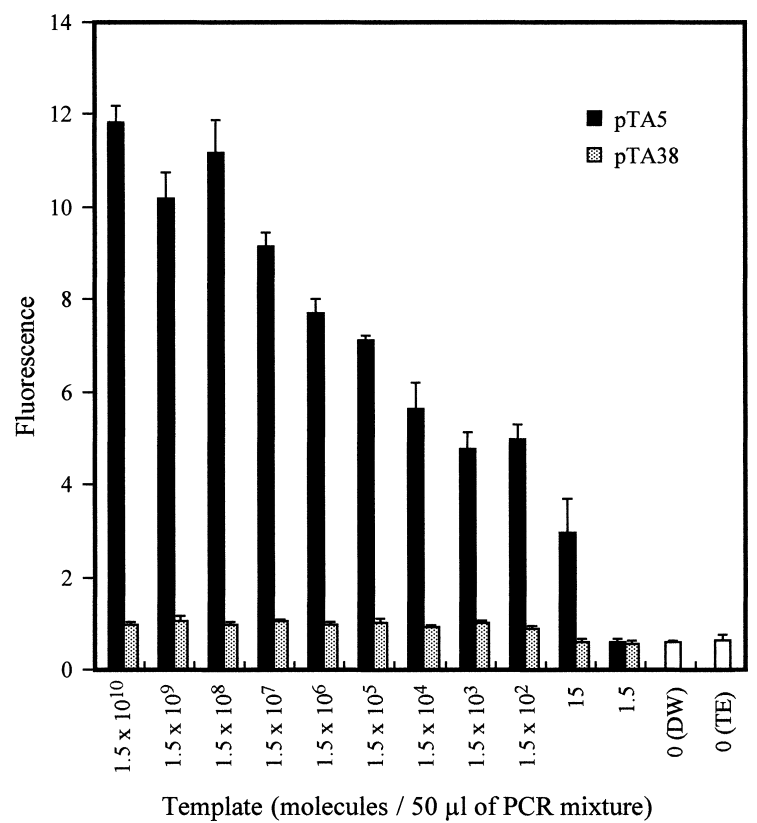

Fig. 4. 5'-Nuclease PCR assay at different concentrations of template DNA. The primers A5F and A5R were used in the assay. The number of molecules was calculated from a concentration of plasmid DNA ranging from $50 \mathrm{ng}$ to $5 \mathrm{ag}$. pTA5 had a sequence identical to the probe, whereas pTA38 had 1 mismatch. For negative controls, distilled water (DW) and TE buffer (TE) was used in place of template DNA. Error bars represent the standard deviation from three independent assays. The result for 15 molecules of pTA5 was significantly different from all other results $(\mathrm{p}<0.05)$.

plate controls at 15 molecules $(\mathrm{p}<0.01)$, and increased with level of template plasmid; whereas the fluorescence of pTA38 remained comparable to the control values at concentrations up to $10^{10}$ molecules. The value of pTA38 at $1.5 \times 10^{10}$ molecules was far less than that of pTA5 at 15 molecules $(p=0.015)$. Hence there is no possibility that non-identical sequences give false positive results. Assuming that the bacteria have a single copy of $16 \mathrm{~S}$ rDNA, the maximum sensitivity of the assay can be calculated as 0.75 cells/ml of seawater sample if the DNA is completely extracted from $50 \mathrm{ml}$ of a seawater sample.

Next, the specificity of the CF8 probe was examined with chromosomal DNA. The strains examined and their sequences in the regions of the probe and primers are shown in Fig. 1. In the PCR-direct sequence of the previous study), only the strains of group A5 gave structures identical to the primers $\mathrm{A} 5 \mathrm{~F}$ and $\mathrm{A} 5 \mathrm{R}$, and the probe $\mathrm{CF} 8$, whereas the other strains had mismatches in the primers, probe or both. Cytophaga latercula, Psychroflexus gondwanensis and Salegentibacter salegenes are the species most closely
A

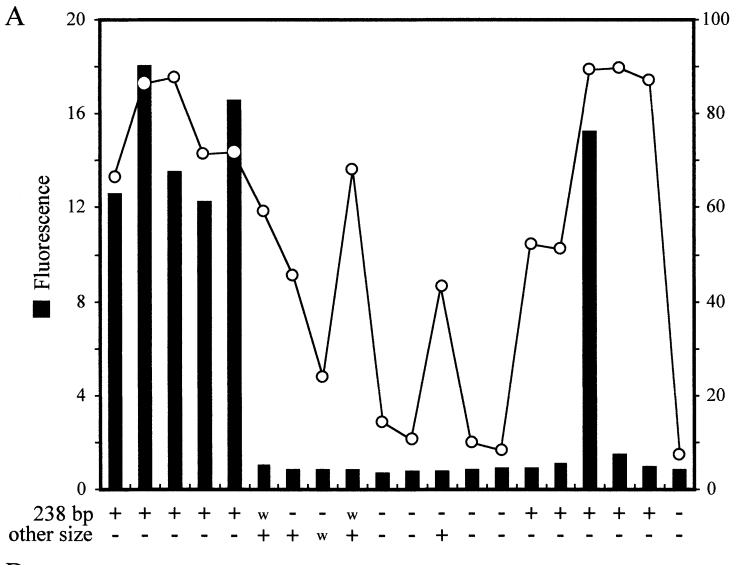

B

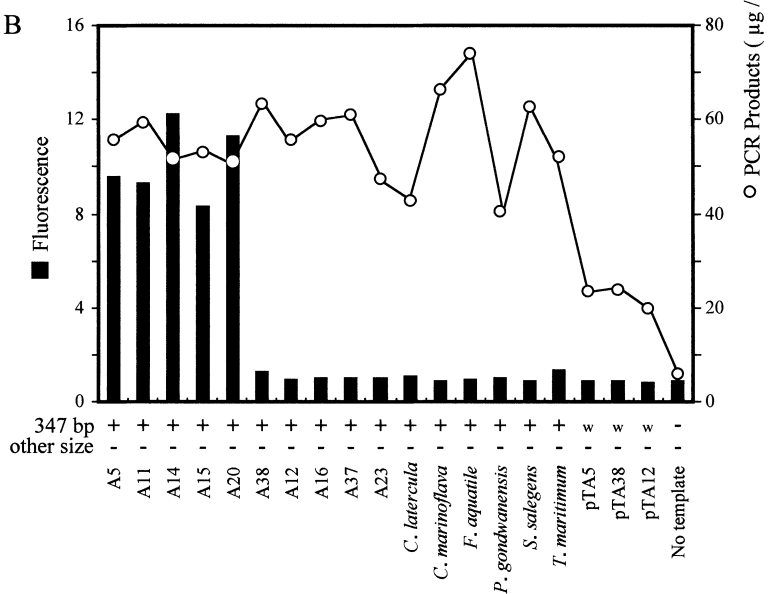

Fig. 5. 5'-Nuclease PCR assay for chromosomal DNA extracted from different bacterial strains and plasmid DNA using two different sets of PCR primers, A5F/A5R (A) and 27F/338R (B). The expected sizes of PCR products are 238 and $347 \mathrm{bp}$, respectively. The sizes of PCR products were determined by an agarose-gel electrophoresis; +, significant; w, weak; -, no amplification. The amount of PCR template was $50 \mathrm{pg} / 50 \mu \mathrm{l}$ of PCR mixture for plasmids. Other abbreviations are shown in Fig. 1.

related to group A5 in $16 \mathrm{~S}$ rDNA phylogenetic analysis.

As shown in Fig. 5A, PCR products of expected size (238 bp) were obtained for the plasmid DNAs and for the chromosomal DNAs of A5 group strains, Salegentibacter salegenes and Tenacibaculum maritimum. However, hybridization was only observed with the A5 group and pTA5. Furthermore, when the universal primers $27 \mathrm{~F}$ and 338R applicable to all of the bacteria but not to plasmids were used in place of $\mathrm{A} 5 \mathrm{~F}$ and $\mathrm{A} 5 \mathrm{R}$, the hybridization was observed only with the strains of the A5 group, although fragments of expected size $(347 \mathrm{bp})$ were obtained for all of the bacterial strains (Fig. 5B). Hence it is concluded that CF8 can distinguish the strains of the A5 group from other species. The PCR amplification of Salegentibacter salegenes 


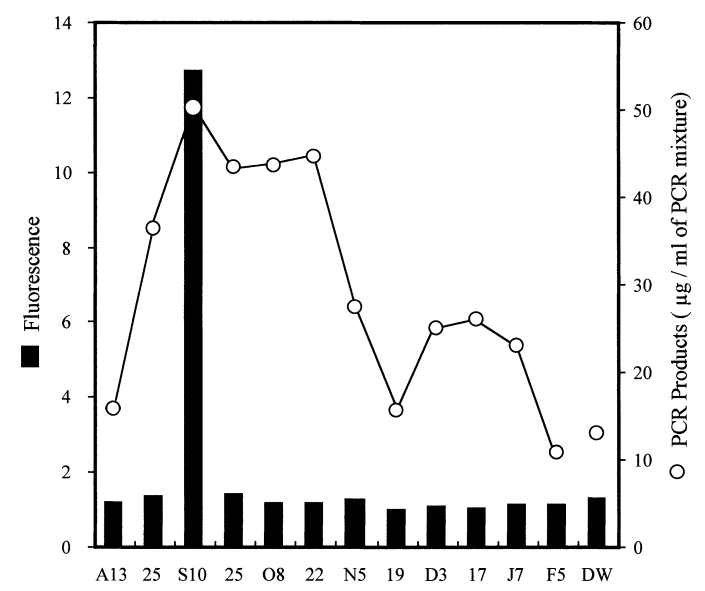

Fig. 6. 5'-Nuclease PCR assay for the seawater samples of Yoshimi Bay, Hibiki-nada Sea, Japan. All PCR products were of expected size (238 bp). A, August; S, September; O, October; N, November; D, December, J, January; F, February.

and Tenacibaculum maritimum indicated that the specificity of A5F/A5R primers was not stringent. Negative reactions with A12, A38 and Cytophaga latercula, which had sequences very similar to that of CF8, indicate that these bacteria did not have the same sequence as CF8, even if intrachromosomal differences were present in 16S rDNA as reported by Rainey et al. ${ }^{11}$.

Finally, we examined whether the combination of A5F/ $\mathrm{A} 5 \mathrm{R}$ primers and the probe $\mathrm{CF} 8$ can detect the same sequence present in bacteria from a natural seawater environment. Figure 6 shows the results of a 5'-nuclease assay for the seawater samples of Yoshimi Bay, Hibiki-nada Sea, Japan. In the bay, seawater temperature decreased from 29 to $9^{\circ} \mathrm{C}$, and the number of $\mathrm{CFU}$ and direct counts was $10^{3-4}$ and $10^{6} / \mathrm{ml}$, respectively. DNA was extracted from seawater by a boiling method, in place of the phenol/chloroform method, to reduce the amount of labor and make the method applicable to many natural samples. As shown in the figure, PCR products were obtained with all of the samples except for those of August 13, November 19 and February 5, and the sizes of PCR products were as expected (238 bp). Note however, that hybridization-dependent fluorescence was observed for the September 10 sample. Then, we examined whether this fluorescence was indeed caused by a sequence identical to CF8. The PCR product for September 10 was cloned into pT7blue $\mathrm{T}$, and the clones were examined with the 5'-nuclease PCR assay. Of 30 clones examined, 25 showed clear increases of fluorescence, whereas four did not (Fig. 7). The fluorescence of clone pSEP115 was half that of the positive clones. Next, the inserted fragments of

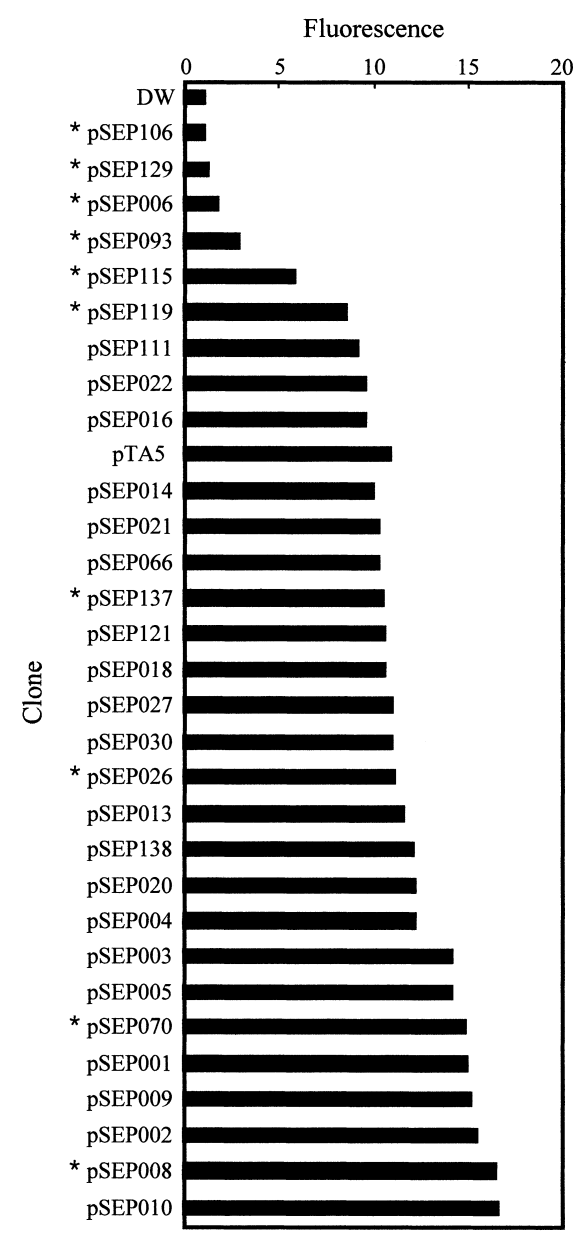

Fig. 7. 5'-Nuclease PCR assay for clonal DNA fragments of the seawater sample of September 10. Asterisks indicate the clones for which sequences were determined.

four hybridization-negative clones, pSEP115 and five positive clones were sequenced to check whether CF8 only hybridized to the same sequence. As shown in Fig. 8 summarizing the sequences, all of the positive clones and pSEP115 had sequence identical to CF8 in the probe region. However, in the probe region of the negative clones, one nucleotide was defected in pSEP106, and one nucleotide was substituted at a different position in pSEP129, pSEP006 and pSEP093. Although pSEP129 had a substitution in the A5R primer region, there was no effect on the result of PCRamplification.

Hence it is concluded that CF8 hybridized only to the identical sequence. The specificity was not affected by the position of the nucleotide substitution or defection in the probe region. The data for pSEP115 indicates a small possibility that the target molecule gave an ambiguous result, when target DNA was extracted by the boiling method, in 


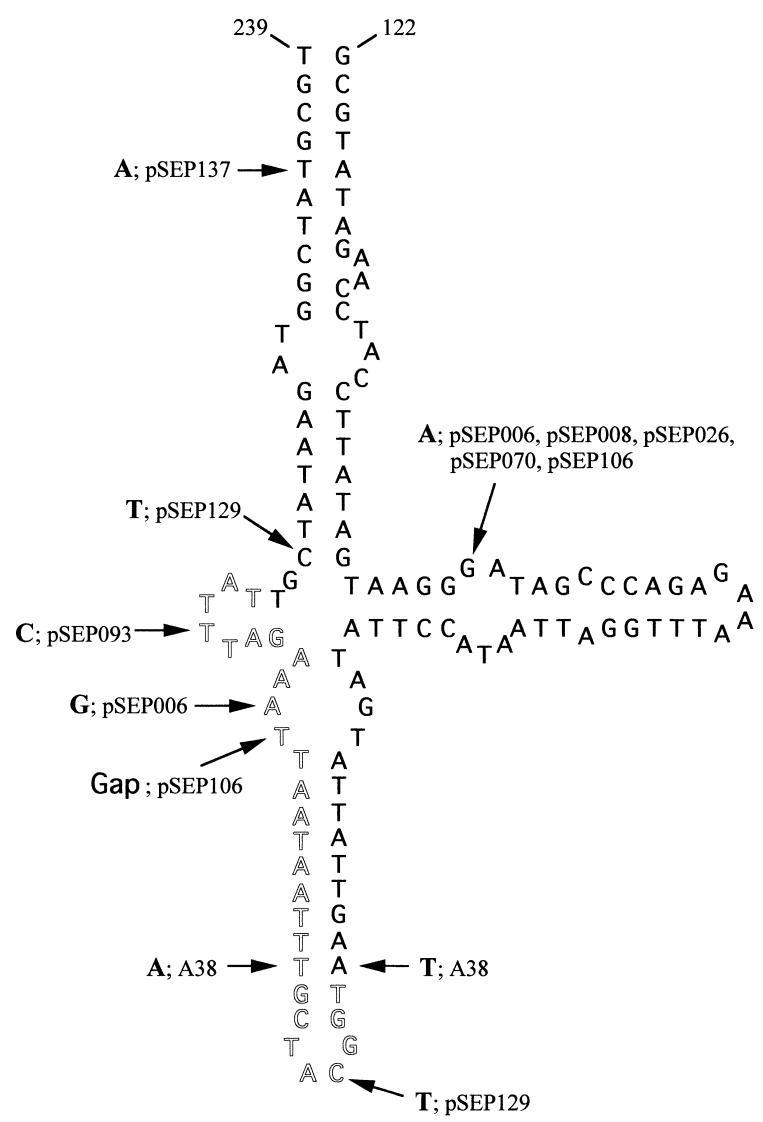

Fig. 8. Structures of CF8 probe regions in clonal DNA fragments. Hollow letters indicate the probe region. The positions of substitutions and defections are indicated with arrows, and substituted nucleotides are written in front of the number of the clone. "A38" is a strain number. The nucleotide positions correspond to those of Escherichia coli ${ }^{1)}$.

contrast to when the template DNAs were extracted by the phenol/chloroform method (Fig. 3 and Fig. 4). The data also indicate diversity among the clonal $16 \mathrm{~S}$ rDNA fragments, which were amplified with A5F/A5R primers. The five positive clones and pSEP115 were divided into 3 clusters; the sequences of pSEP115 and pSEP119 were identical to the sequence of pTA5, pSEP137 had one nucleotide substitution in a stem region, and pSEP008, pSEP026 and pSEP070 had one substitution in the same loop region. On the other hand, the four negative clones gave 4 clusters. pSEP106 had one substitution and one defection. pSEP006 and pSEP129 had two substitutions at different positions, and pSEP093 had one substitution. Many of the substitutions were found in loop regions, and only two were in stem regions. Since the reported frequency of misreading by DNA polymerase ${ }^{12)}$ is not so high as to produce substitutions of two nucleotides in $238 \mathrm{bp}$ of the amplified DNA, the differences found between the clones would seem to reflect the diversity of bacterial $16 \mathrm{~S}$ rDNA that had sequences similar to the A5F and A5R primers. Although the presence of bacteria that had the same sequence as probe CF8 was indicated in the seawater sample, all of the 142 strains isolated from the seawater sample of September 10 gave negative reactions in the 5 '-nuclease PCR assay. This may suggest a small density of the target species in the sample.

\section{Acknowledgments}

The authors express sincere thanks to Dr. Ishida, of Fukuyama University, for giving us the opportunity to work cooperatively. The work was supported by a grant-in-aid from the Ministry of Agricultural, Forestry and Fishery of Japan.

\section{References}

1) Brosius, J., M.L. Poindexter, J. Kennedy and H.F. Noller. 1978. Complete nucleotide sequence of a 16S ribosomal RNA gene from Escherichia coli. Proc. Natl. Acad. Sci. USA 75: 48014805.

2) Holland, P.M., R.D. Abramson, R. Watson and D.H. Gelfand. 1991. Detection of specific polymerase chain reaction product by utilizing the 5' to 3' exonuclease activity of Thermus aquaticus DNA polymerase. Proc. Natl. Acad. Sci. USA 88: 7276-7280.

3) Ishida, Y. 1998. Algicidal microorganisms related to harmful algal blooms and their ecology. Microbes Environ. 13: 101-107 (In Japanese).

4) Lee, L.G., C.R. Connell and W. Bloch. 1993. Allelic discrimination by nick-translation PCR with fluorogenic probes. Nucleic Acids Res. 21: 3761-3766.

5) Maeda, T., M. Murakami, S. Ohsugi, M. Furushita, A. Mitsutani and T. Shiba. 1998. Perspectives of the development of $16 \mathrm{~S}$ rDNA probe specific for algicidal and/or algal-lytic gliding bacteria. Fisheries Sci. 64: 861-865.

6) Maeda, T., Y. Matsuo, M. Furushita and T. Shiba. 2003. Seasonal dynamics in a coastal Vibrio community examined by a rapid clustering method based on 16S rDNA. Fisheries Sci. 69: 385394.

7) Mitsutani, A., K. Takesue, M. Kirita and Y. Ishida. 1992. Lysis of Skeletonema costatum by Cytophaga sp. isolated from the coastal water of the Ariake Sea. Nippon Suisan Gakkaishi 58: 2159 2167.

8) Mitsutani, A. 1997. Ecological and physiological studies on algal lytic bacteria in lakes and coastal waters. J. Natl. Fish. Univ. 45: $165-257$.

9) Paul, J.H. and B. Myers. 1982. Fluorometric determination of DNA in aquatic microorganisms by use of Hoechst 33258. Appl. Environ. Microbiol. 43: 1393-1399.

10) Porter, K.G. and Y.S. Feig. 1980. The use of DAPI for identifying and counting aquatic microflora. Limnol. Oceanogr. 25: 943948.

11) Rainey, F.A., N.L. Ward-Rainey, P.H. Janssen, H. Hippe and E. Stackebrandt. 1996. Clostridium paradoxum DSM 7308Y contains multiple 16S rRNA genes with heterogeneous intervening 
sequences. Microbiology 142: 2087-2095.

12) Saiki, R.K., D.H. Gelfand, S. Stoffel, S.J. Scharf, R. Higuchi, G.T. Horn, K.B. Mullis and H.A. Erlich. 1988. Primer-directed enzymatic amplification of DNA with a thermostable DNA polymerase. Science 239: 487-491.

13) Sambrook, J., E.F. Fritch and T. Maniatis. 1989. Molecular Cloning, a Laboratory Manual, 2nd. ed., Cold Spring Harbor Laboratory Press, New York.

14) Shiba, T. 1992. The genus Erythrobacter, p. 2485-2489. In A. Balows, H.G. Trüper, M. Dworkin, W. Harder and K.H. Schleifer (ed.), The Prokaryotes, Springer-Verlag, New York.

15) Shiba, T., M. Murakami, K. Ohiso, Y. Matsuo and T. Maeda. 1998. Specificity of a fluorogenic DNA probe for species of a Vibrio core group. Microbes Environ. 13: 129-135.

16) Shiba, T., M. Sasaki, B. You, I. Yoshinaga and T. Maeda. 2001. Hybridization independent increase of fluorescence in a 5 , nuclease PCR assay. Microbes Environ. 16: 117-120.

17) Taga, N. 1968. Some ecological aspects of marine bacteria in the Kuroshio current. Bull. Misaki Mar. Biol. Kyoto Univ. 12: 5676. 